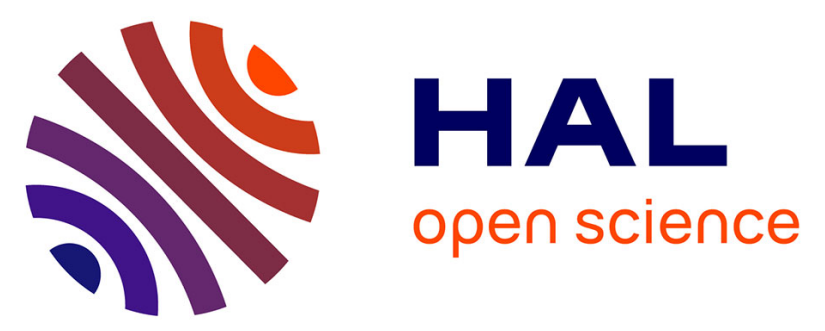

\title{
Investigation of fission chamber response in the frame of fuel debris localization measurements at Fukushima Daiichi
}

Adrien Sari, Cheick Thiam, Karim Boudergui, Frédérick Carrel, Romain Coulon, Jonathan Dumazert, Camille Frangville, Hassen Hamrita, Frédéric Lainé, Mathieu Trocmé, et al.

\section{To cite this version:}

Adrien Sari, Cheick Thiam, Karim Boudergui, Frédérick Carrel, Romain Coulon, et al.. Investigation of fission chamber response in the frame of fuel debris localization measurements at Fukushima Daiichi. Radiation Measurements, 2020, 130, pp.106223. 10.1016/j.radmeas.2019.106223 . hal-03489020

\section{HAL Id: hal-03489020 https://hal.science/hal-03489020}

Submitted on 4 Jan 2022

HAL is a multi-disciplinary open access archive for the deposit and dissemination of scientific research documents, whether they are published or not. The documents may come from teaching and research institutions in France or abroad, or from public or private research centers.
L'archive ouverte pluridisciplinaire HAL, est destinée au dépôt et à la diffusion de documents scientifiques de niveau recherche, publiés ou non, émanant des établissements d'enseignement et de recherche français ou étrangers, des laboratoires publics ou privés. 


\section{Investigation of fission chamber response in the frame of fuel debris localization}

\section{measurements at Fukushima Daiichi}

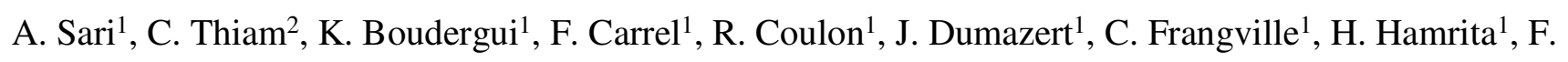
Lainé$^{1}$, M. Trocmé ${ }^{1}$, B. Krausz ${ }^{3}$, R. Pissarello ${ }^{3}$, R. Delalez ${ }^{3}$

${ }^{1}$ CEA, LIST, Laboratoire Capteurs et Architectures Electroniques, 91191 Gif-sur-Yvette Cedex, France

${ }^{2}$ CEA, LIST, Laboratoire National Henri Becquerel (LNE-LNHB), 91191 Gif-sur-Yvette Cedex, France

${ }^{3}$ ONET TECHNOLOGIES, Nuclear Decommissioning, 26700, Pierrelatte, France

*Corresponding author: Adrien Sari (tel.: +33 1690831 04, e-mail address: adrien.sari@cea.fr)

\section{Abstract}

This work aims at assessing the performance of a ${ }^{235} \mathrm{U}$ enriched fission chamber in order to localize fuel debris, prior to dismantling operations, in a flooded primary containment vessel of a damaged nuclear reactor such as Fukushima Daiichi. Based on both a comprehensive scan of the environment and the detection of neutrons emitted by the melted core, fuel debris can be localized. In this paper, we carry out a simulation study using the MCNP6 code to investigate fission chamber response in the frame of fuel debris localization measurements in a damaged nuclear reactor. The CFUF34 fission chamber (manufactured by PHOTONIS) and the primary containment vessel of Fukushima Daiichi Unit 1 were chosen to conduct this work. Impact of different parameters were investigated with MCNP6, such as: neutron energy, water temperature, fission chamber position (altitude, lateral shift, and rotation), and sensitivity loss due to sediments potentially covering fuel debris. In summary, we show that fuel debris should be sought by their thermal neutron signature at a distance of a few centimeters and that potential rotational movements of the fission chamber up to $60^{\circ}$ have a limited impact on signals measured. We also show that sensitivity loss due to sediments potentially covering fuel debris has been evaluated on the order of a factor 10 considering a $30 \mathrm{~cm}$-thick sediment layer. On the other hand, experiments were performed to assess the impact of a 
strong gamma dose rate on fission chamber measurements. These irradiation trials involved a CFUE32 fission chamber (also manufactured by PHOTONIS) available in our laboratory and three different irradiation means: an X-ray tube, an ${ }^{192} \mathrm{Ir}$ source, and a linear electron accelerator. These experiments enable to draw the conclusion that the fission chamber is not impacted by the gamma dose rate up to $10^{4}$ Gy.h ${ }^{-1}$, which is in good agreement with specifications provided by the manufacturer (PHOTONIS). In addition, no performance degradation was observed after an integrated gamma dose of 2200 Gy on the fission chamber in a 10 minute irradiation. However, when the fission chamber is irradiated by gamma dose rates above $10^{4} \mathrm{~Gy} \cdot \mathrm{h}^{-1}$ (upper limit of the operating domain specified by PHOTONIS), a significant gamma background is observed. Nevertheless, as the gamma dose rates at Fukushima Daiichi should not exceed $10^{3}$ Gy.h ${ }^{-1}$, fission chamber measurements performed towards fuel debris localization in the Primary Containment Vessels (PCV) of the units would not be affected by the severe gamma-ray irradiation.

Keywords: Fukushima Daiichi; fuel debris localization; neutron flux measurement; fission chamber; MCNP6 simulation; gamma irradiation trials

\section{Introduction}

Decommissioning of a nuclear power plant is an important and complex task. This is even more critical when the reactor has suffered from severe damage to the point of causing the core meltdown, which lead to leakage of melted nuclear fuel outside the reactor vessel, in the Primary Containment Vessel (PCV). Three units of the Fukushima nuclear power plant encountered such event on the $11^{\text {th }}$ of March 2011. Water was injected into the three damaged PCVs to limit core meltdown. Since 2011, several investigations have been carried out with the objectives of inspecting the PCVs and trying to localize fuel debris in order to prepare dismantling operations. These investigations were performed either by visual inspection thanks to video cameras or by muons measurement [1-6]. Measurement of muons gives an overview of main structures based on the distribution of surface densities. However, spatial resolution of detectors and the analysis method do not enable the detection of small objects in the reactor, fragments of fuel debris for instance [7]. 
Thus, a precise localization of fuel debris is not known at the current time. Moreover, the diagnosis could be significantly different between the three units.

In a recent past, CEA List has investigated, in partnership with ONET Technologies, the development of a detection system, which could be integrated on the carrier of a robot, to perform neutron measurements in order to localize fuel debris in the flooded PCV of the Fukushima units. Fuel debris can be localized thanks to the detection of neutrons emitted by the melted core components. Nevertheless, a mapping based on Xray and gamma spectrometry could also be considered as photons are emitted by fission products such as ${ }^{134} \mathrm{Cs},{ }^{137} \mathrm{Cs}$ or ${ }^{237} \mathrm{~Np}[8,9]$. However, the correlation between the position of fuel debris (neutron emitters) and volatile fission products (gamma emitters) is uncertain. Correction factors would be required and, in practical, difficult to implement in the Fukushima units. Hence, the localization of fuel debris according to their neutron signature represents a solution of interest.

The deployment of a neutron detection system at Fukushima Daiichi may be confronted to several constraints: investigation in a high radiation dose environment (up to $10^{3} \mathrm{~Gy} \cdot \mathrm{h}^{-1}$ ), measurements performed underwater, cramped access to enter inside the PCV, and the acquisition time among others. In this measurement configuration, the main neutron signal would be coming from thermal neutrons, with relatively low fluxes (from $10^{-1}$ to $10^{3} \mathrm{n} \cdot \mathrm{cm}^{-2} \cdot \mathrm{s}^{-1}$ ). One could use ${ }^{3} \mathrm{He}$ proportional counters, which are the gold standard for neutron detection for many applications, but high risks of sensitivity degradation [10] due to the strong gamma dose rate background encountered at Fukushima Daiichi renders these detectors unsuitable. Considering the strong measurement constraints faced in this project [11], the choice of neutron detectors was oriented towards small fission chambers.

In this paper, we build a model of fuel debris for the MCNP6 code [12]. Then, thanks to MCNP6 simulations, we characterize the neutron flux and investigate the response variability of the CFUF34 fission chamber (manufactured by PHOTONIS) in the frame of fuel debris localization measurements in a damaged nuclear reactor (Fukushima Daiichi unit 1). The CFUF34 fission chamber was chosen mainly for 


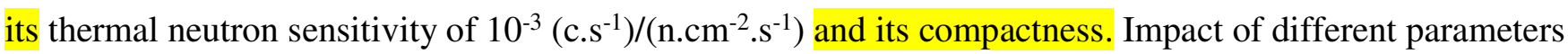
were investigated, such as: fission chamber position with respect to fuel debris (altitude, lateral shift, and rotation), and sensitivity loss due to sediments potentially covering fuel debris. On the other hand, experiments were performed to assess the impact of a strong gamma dose rate on fission chamber measurements. Results obtained with three different irradiation means — an X-ray tube, an ${ }^{192}$ Ir source, and a linear electron accelerator - emitting gamma-rays characterized by different energy spectra at different dose rates will be exposed.

\section{MCNP6 model of fuel debris}

A model of fuel debris is required in order to evaluate measurement sensitivity obtained with a fission chamber by MCNP6 simulation, on the basis of realistic and comprehensive consideration of the source term. Significant discrepancies can be observed in the fuel debris models which are available in the literature. This can be explained by the fact that no core melt samples from the Fukushima Daiichi damaged reactors are available up to now and will not be before dismantling operations start. Moreover, both the density and the chemical composition are expected to be different for the three damaged units as amounts of water injected and accident kinetics differ between the units. Fuel debris are likely to be heterogeneous, composed of different layers, and to reveal complex chemical mixtures and different crust compositions [13].

An et al. [14] conducted a melting and solidification experiment in a cold crucible using an induction heating technique in order to investigate the composition of the molten core at the Fukushima Daiichi unit 1 [14]. This paper shows that fuel debris would be composed of two layers: an upper layer which is rich in metal $\left(7.0\right.$ g. $\left.\mathrm{cm}^{-3}\right)$, containing a high amount of boron carbide $\left(\mathrm{B}_{4} \mathrm{C}\right.$, a neutron absorber); and a lower layer which is rich in oxide $\left(7.9 \mathrm{~g} . \mathrm{cm}^{-3}\right)$, containing a low amount of $\mathrm{B}_{4} \mathrm{C}$. Bonneville et al. [15] provide a model of fuel debris determined with an evaluation code known as ASTEC (Accident Source Term Evaluation Code) [16]. This model is composed of five layers: fuel debris, heavy metallic layer, oxide layer, light 
metallic layer, and debris layer. Thicknesses of each layer have not been reported. Nevertheless, consensus is reached on the fact that fuel debris: are likely to be composed of species such as $\mathrm{U}, \mathrm{UO}_{2}, \mathrm{Zr}, \mathrm{ZrO}_{2}, \mathrm{~B}_{4} \mathrm{C}$ and steel; would consist of multiple layers (metal-rich and oxide-rich layers).

In the present work, fuel debris located in flooded PCVs at Fukushima Daiichi will be simulated with MCNP6 considering a $10 \mathrm{~cm}$-thick single layer with a chemical composition determined from the results obtained with ASTEC. First, masses in kg per species and per layer for the three Fukushima Daiichi units were taken from the paper published by Bonneville et al. [15] and were converted in weight percentages. Secondly, we retained the top layer (light metallic layer known as "magma 3" with the ASTEC terminology) as fuel debris are located at the bottom of the reactor and measurements would be carried out with the fission chamber positioned above the fuel debris. In other words, the fission chamber would be sensitive to neutrons emitted from the top of fuel debris, and the neutron emission of layers below would be strongly attenuated. Thirdly, in order to make an average model of fuel debris for the three Fukushima Daiichi units, we took the weight percentages of each species for the three units and calculated mean values. Weight percentages of each species were then calculated for each chemical element. The chemical composition of the MCNP6 model considering a uranium enrichment of $3 \%$ is given in Table 1. 
Table 1. Chemical composition of the MCNP6 simulation model of fuel debris and the isotopic composition, considering a uranium enrichment of $3 \%$.

\begin{tabular}{|c|c|c|c|}
\hline \multirow{2}{*}{ Element } & \multicolumn{3}{|c|}{ Weight percentages per element and per isotope } \\
\hline & $\begin{array}{l}\text { Weight } \\
\text { percentages per } \\
\text { element }(\%)\end{array}$ & Isotope & $\begin{array}{l}\text { Weight percentages } \\
\text { per isotope }(\%)\end{array}$ \\
\hline \multirow{2}{*}{$\mathrm{U}$} & \multirow{2}{*}{45.26} & ${ }^{235} \mathrm{U}$ & 1.35 \\
\hline & & ${ }^{238} \mathrm{U}$ & 43.91 \\
\hline $\mathrm{O}$ & 12.69 & ${ }^{16} \mathrm{O}$ & 12.69 \\
\hline \multirow{5}{*}{$\mathrm{Zr}$} & \multirow{5}{*}{25.89} & ${ }^{90} \mathrm{Zr}$ & 13.32 \\
\hline & & ${ }^{91} \mathrm{Zr}$ & 2.91 \\
\hline & & ${ }^{92} \mathrm{Zr}$ & 4.44 \\
\hline & & ${ }^{94} \mathrm{Zr}$ & 4.50 \\
\hline & & ${ }^{96} \mathrm{Zr}$ & 0.72 \\
\hline \multirow{2}{*}{$\mathrm{B}$} & \multirow{2}{*}{0.11} & ${ }^{10} \mathrm{~B}$ & 0.02 \\
\hline & & ${ }^{11} \mathrm{~B}$ & 0.09 \\
\hline $\mathrm{C}$ & 0.03 & ${ }^{12} \mathrm{C}$ & 0.03 \\
\hline \multirow{4}{*}{$\mathrm{Fe}$} & \multirow{4}{*}{11.54} & ${ }^{54} \mathrm{Fe}$ & 0.67 \\
\hline & & ${ }^{56} \mathrm{Fe}$ & 10.58 \\
\hline & & ${ }^{57} \mathrm{Fe}$ & 0.25 \\
\hline & & ${ }^{58} \mathrm{Fe}$ & 0.03 \\
\hline \multirow{4}{*}{$\mathrm{Cr}$} & \multirow{4}{*}{2.88} & ${ }^{50} \mathrm{Cr}$ & 0.12 \\
\hline & & ${ }^{52} \mathrm{Cr}$ & 2.42 \\
\hline & & ${ }^{53} \mathrm{Cr}$ & 0.27 \\
\hline & & ${ }^{54} \mathrm{Cr}$ & 0.07 \\
\hline \multirow{5}{*}{$\mathrm{Ni}$} & \multirow{5}{*}{1.6} & ${ }^{58} \mathrm{Ni}$ & 1.09 \\
\hline & & ${ }^{60} \mathrm{Ni}$ & 0.42 \\
\hline & & ${ }^{61} \mathrm{Ni}$ & 0.02 \\
\hline & & ${ }^{62} \mathrm{Ni}$ & 0.06 \\
\hline & & $\frac{{ }^{64} \mathrm{Ni}}{}$ & 0.01 \\
\hline
\end{tabular}


In addition, the density of fuel debris $-7 \mathrm{~g} \cdot \mathrm{cm}^{-3}$ - was taken from An et al. [14]. The MCNP6 model of duel debris also includes $S(\alpha, \beta)$ thermal neutron scattering data (given for a temperature of $293.6 \mathrm{~K}$ ) in order to avoid unsuitable free gas treatment at low neutron energies. $S(\alpha, \beta)$ data were used for the following elements: uranium contained in $\mathrm{UO}_{2}$; oxygen contained in $\mathrm{UO}_{2}$; zirconium; and ${ }^{56} \mathrm{Fe}$.

Furthermore, the main neutron-emitting nuclide in the melted core is expected to be ${ }^{244} \mathrm{Cm}$ by spontaneous fission due to its high specific emission $\left(1.08 \times 10^{7} \mathrm{n} \cdot \mathrm{s}^{-1} \cdot \mathrm{g}^{-1}[17]\right)$. In the frame of the MCNP6 model of fuel debris, neutrons are produced according to a Watt fission spectrum of the ${ }^{244} \mathrm{Cm}$ nuclide $\left(E_{\text {mean }}=\right.$ 2.1 $\mathrm{MeV})$. This spectrum is computed using the following function:

$$
f(E)=C \exp (-E / a) \sinh (\sqrt{b E})
$$

in which, $C$ is a normalization factor; $a$ and $b$ are specific constants. For the case of ${ }^{244} \mathrm{Cm}$ spontaneous fission, $a$ is equal to $902.5 \mathrm{keV}$ and $b$ is equal to $3.72 \mathrm{MeV}^{-1}$ [18].

\section{Characterization of the neutron flux}

As fission chamber measurements dedicated to fuel debris localization are meant to be carried out underwater in the flooded PCVs of the Fukushima units, first, we evaluated the effect of water on neutron energy, and the effect of water temperature on the neutron flux.

\subsection{Effect of water on neutron energy}

An isotropic point source emitting neutrons according to a ${ }^{244} \mathrm{Cm}$ energy spectrum, representing a hot spot of fuel debris, was simulated at the center of a $25 \mathrm{~cm}$-radius sphere. The sphere was crossed by a horizontal plane through the center. The bottom hemisphere was filled with concrete whereas the top hemisphere was filled with water. Concentric spheres of increasing size with radii from 1 to $24 \mathrm{~cm}$ by $1 \mathrm{~cm}$ steps were then simulated inside the $25 \mathrm{~cm}$-radius sphere (all spheres being centered on the neutron source). A scheme of the simulation model is shown in Fig. 1. Neutrons were tracked on the surfaces of each top hemispheres using an F1 tally in MCNP6 (neutron current integrated over a surface). The neutron flux i.e., the number 
of neutrons per $\mathrm{cm}^{2}$ and per neutron emitted by the source, was obtained by dividing the number of neutrons crossing each hemisphere surface by the area of the latter expressed in $\mathrm{cm}^{2}$. Fig. 2 presents the neutron flux as a function of the distance from a hot spot of fuel debris. The neutron spectrum was divided in three energy components:

- thermal neutrons (energy lower than $0.6 \mathrm{eV}$ );

- $\quad$ epithermal neutrons (energy from $0.6 \mathrm{eV}$ to $1 \mathrm{MeV}$ );

- $\quad$ fast neutrons (energy above $1 \mathrm{MeV})$.

We can see that the fast neutron component decreases rapidly over the distance from the hot spot of fuel debris due to the strong moderation effect of water. The maximum value of the thermal neutron flux is reached at $3 \mathrm{~cm}$ where thermal neutrons represent $23 \%$ of the total neutron flux. The thermal neutron flux becomes predominant above a distance of $5 \mathrm{~cm}$, and remains higher than $10^{-3}$ neutrons per $\mathrm{cm}^{2}$ and per source neutron around $10 \mathrm{~cm}$. The thermal neutron flux is then significantly reduced when the distance increases and becomes lower than $10^{-4}$ neutrons per $\mathrm{cm}^{2}$ and per source neutron at $25 \mathrm{~cm}$ from the hot spot of fuel debris. Regarding measurements performed at Fukushima Daiichi, we can conclude that the fission chamber will have to be sensitive to thermal neutrons and brought at a few centimeters from the fuel debris.

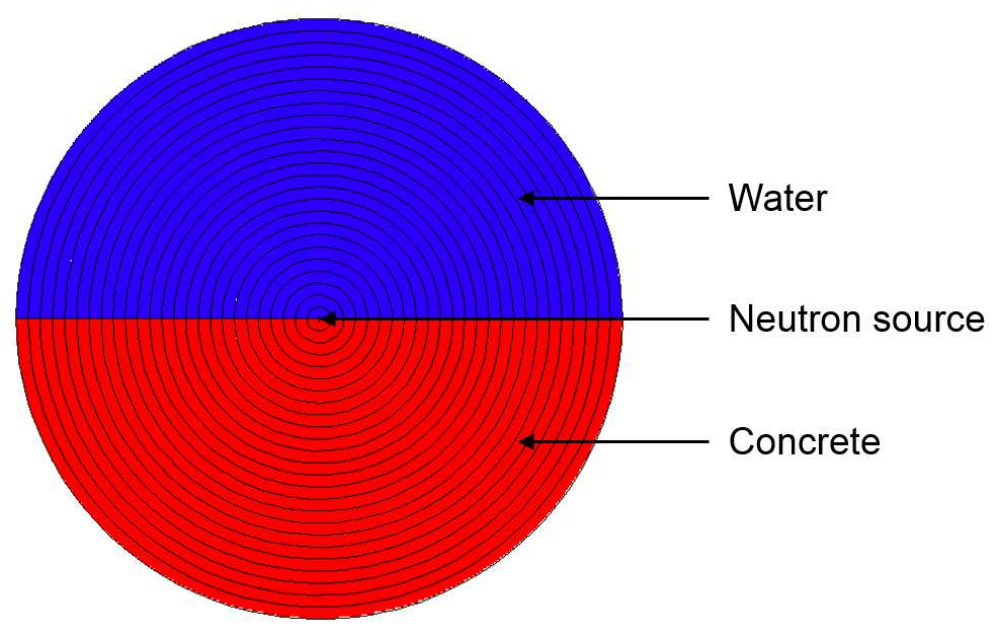

Fig. 1. Scheme of the MCNP6 model used to characterize the neutron flux. 


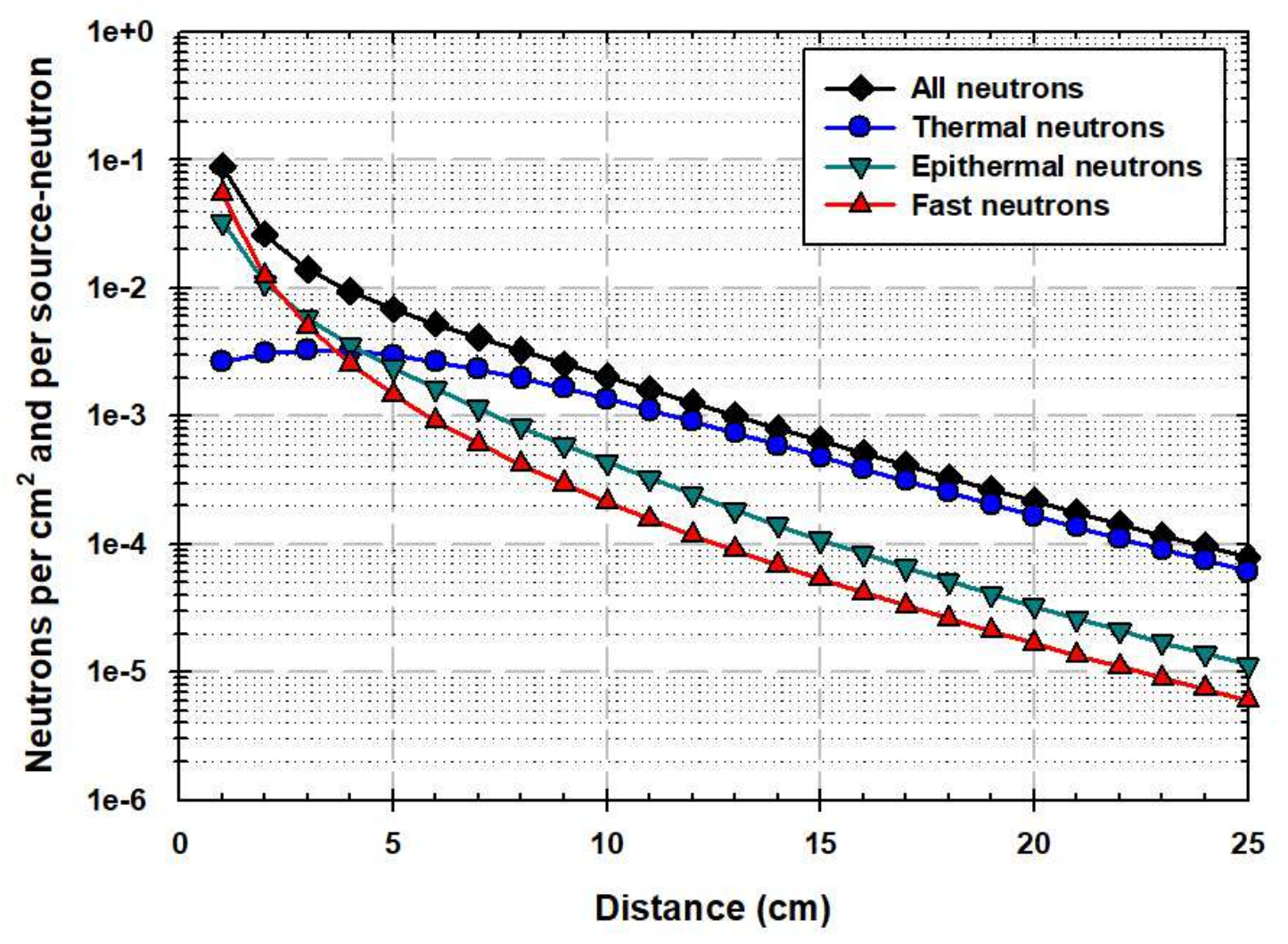

Fig. 2. Neutron fluxes as a function of the distance from a hot spot of fuel debris.

\subsection{Effect of water temperature on the thermal neutron flux}

The water temperature can be modified in the MCNP6 simulation model by taking into account using the appropriate $S(\alpha, \beta)$ thermal neutron scattering data. For the case of light water, $S(\alpha, \beta)$ data are available for two temperatures of interest in the frame of this study: $293.6 \mathrm{~K}$ (about $20^{\circ} \mathrm{C}$ ) and $350 \mathrm{~K}\left(\right.$ about $77^{\circ} \mathrm{C}$ ). Fig. 3 shows the thermal neutron flux as a function of the distance from a hot spot of fuel debris for these two water temperatures. Results show that water temperature has a low impact, with a relative difference under $1 \%$ at $3 \mathrm{~cm}$ and around $10 \%$ at $25 \mathrm{~cm}$. Regarding measurements performed at Fukushima Daiichi, we can conclude that the sensitivity of fission chamber measurements will not be strongly impacted by the water temperature which is assumed to be in between the two water temperatures considered previously. In the following of this study, MCNP6 simulations will be performed considering a water temperature of $293.6 \mathrm{~K}$. 


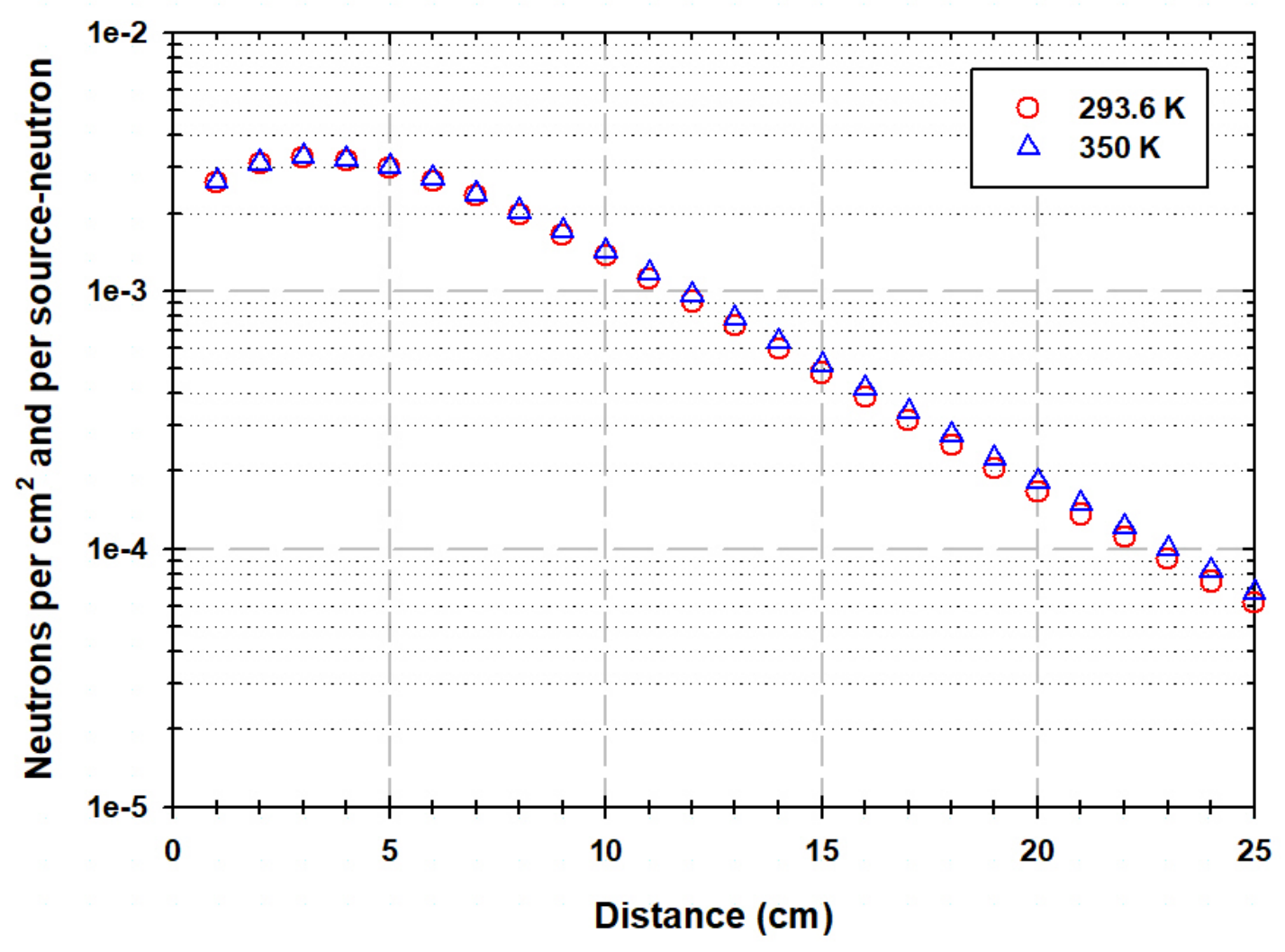

Fig. 3. The thermal neutron flux as a function of the distance from a hot spot of fuel debris for either a water temperature of $293.6 \mathrm{~K}$ or $350 \mathrm{~K}$.

\section{Simulation of fission chamber measurements at Fukushima Daiichi unit 1}

\subsection{Choice of the CFUF34 fission chamber}

The fission chamber chosen to carry out neutron measurements in the flooded PCVs of the Fukushima units to localize fuel debris should be sensitive to thermal neutrons. In addition, considering deployment and measurement constraints at Fukushima Daiichi, the fission chamber should be compact, insensitive to gamma-rays, and present waterproof properties. The CFUF34 fission chamber manufactured by PHOTONIS would be well-adapted thanks to its: compactness (cylindrical shape, $4.7 \mathrm{~mm}$ of diameter and $85 \mathrm{~mm}$ of length); sensitivity to thermal neutrons in pulse mode of $10^{-3}\left(\mathrm{c} \cdot \mathrm{s}^{-1}\right) /\left(\mathrm{n} \cdot \mathrm{cm}^{-2} \cdot \mathrm{s}^{-1}\right)$; insensitivity to 
gamma-rays up to $10^{5} \mathrm{~Gy} \cdot \mathrm{h}^{-1}$; and waterproof properties. In the following, neutron measurements will be simulated using a CFUF34 fission chamber.

\subsection{MCNP6 model of the PCV}

For this study, the environment of the PCV of Fukushima Daiichi unit 1 was chosen. The PCV is made of concrete and has a cylindrical geometry with an internal diameter of 5 meters and a height of 8.5 meters. Side walls are $50 \mathrm{~cm}$-thick. In the PCV of unit 1, the water level is up to 3 meters. Using the MCNP6 model of fuel debris presented previously, fuel debris are simulated according to a cylindrical shape and are embedded in the concrete slab located at the bottom of the PCV. The volume source emits neutrons in an isotropic manner with a ${ }^{244} \mathrm{Cm}$ energy spectrum. The head of the CFUF34 fission chamber is simulated above and pointing towards the top of fuel debris. Fig. 4 shows a view of the MCNP6 simulation model for a $50 \mathrm{~cm}$ large fuel debris cylinder. In order to estimate the response of the fission chamber, we calculate the fission rate in the ${ }^{235} \mathrm{U}$-enriched deposit i.e., the number of fission reactions per neutron emitted by the source, thanks to an F4 tally in MCNP6.
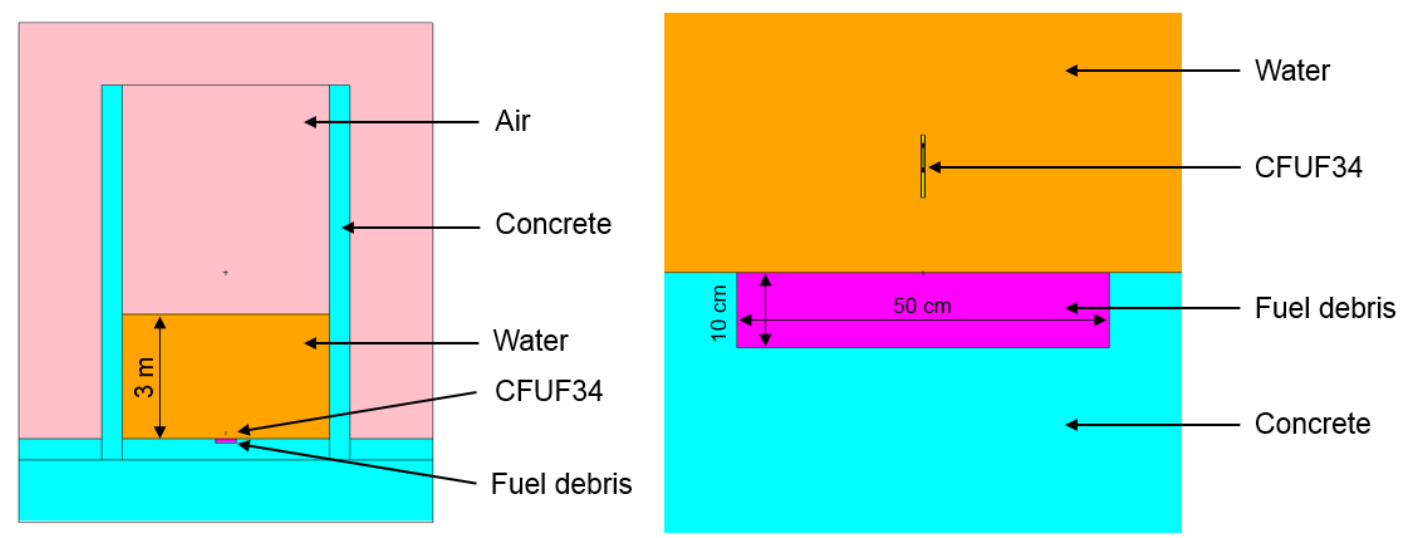

Fig. 4. On the left: view of the MCNP6 model representing the PCV of Fukushima Daiichi unit 1. On the right: focus on the CFUF34 fission chamber immersed in the flooded PCV and pointing towards a cylindrical block of fuel debris. 


\subsection{Effect of fission chamber positioning}

Three effects of fission chamber positioning during measurements were evaluated by MCNP6 simulation: altitude (vertical movement from fuel debris); lateral shift (horizontal movement at $1 \mathrm{~cm}$ above fuel debris); and rotation (see further Fig. 7). First, simulations were performed with the fission chamber placed at different altitudes from fuel debris, between 1 and $20 \mathrm{~cm}$ by $1 \mathrm{~cm}$ steps. Fig. 5 shows the fission chamber response according to the altitude from a $50 \mathrm{~cm}$-large fuel debris cylinder. The fission chamber response increases rapidly when the fission chamber gets closer to fuel debris. When moving the fission chamber from an altitude of $1 \mathrm{~cm}$ to an altitude of $15 \mathrm{~cm}$, the fission chamber response would be reduced by a factor on the order of 10.

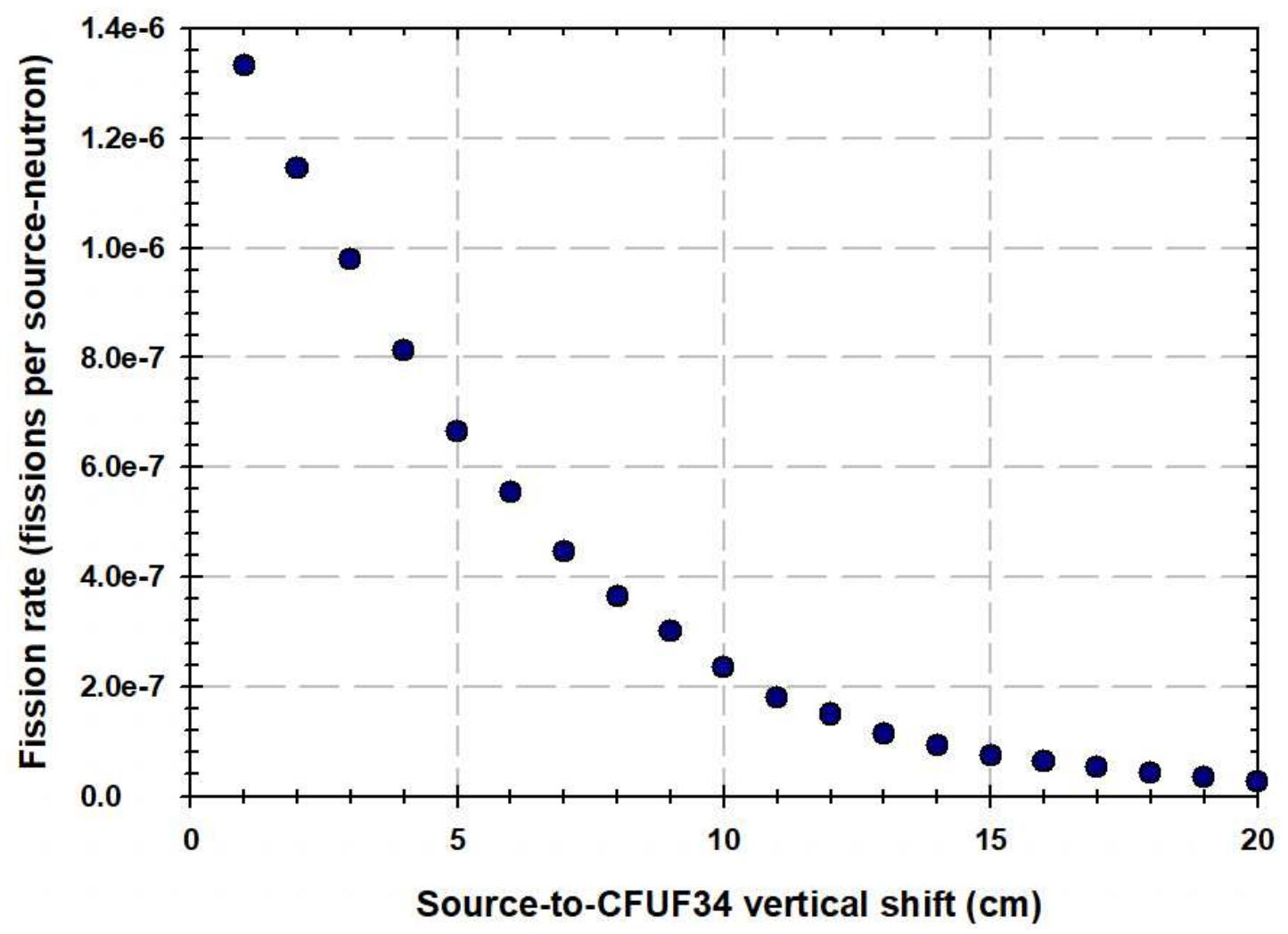

Fig. 5. The fission chamber response as a function of altitude from a $10-\mathrm{cm}$ thick fuel debris cylinder with a diameter of $50 \mathrm{~cm}$ (see Fig. 4). 
Secondly, simulations were performed with the fission chamber placed at an altitude of $1 \mathrm{~cm}$ from fuel debris and with different lateral shifts from 0 to $20 \mathrm{~cm}$ by $1 \mathrm{~cm}$ steps. Fig. 6 shows the fission chamber response according to the lateral shift for the case of a $10 \mathrm{~cm}$-thick fuel debris cylinder with a diameter of $10 \mathrm{~cm}$. When the fission chamber is positioned above the center of a $10 \mathrm{~cm}$-thick and 10-cm large fuel debris cylinder and then shifted $20 \mathrm{~cm}$ on the side, the fission chamber response varies by more than a factor of 4 .

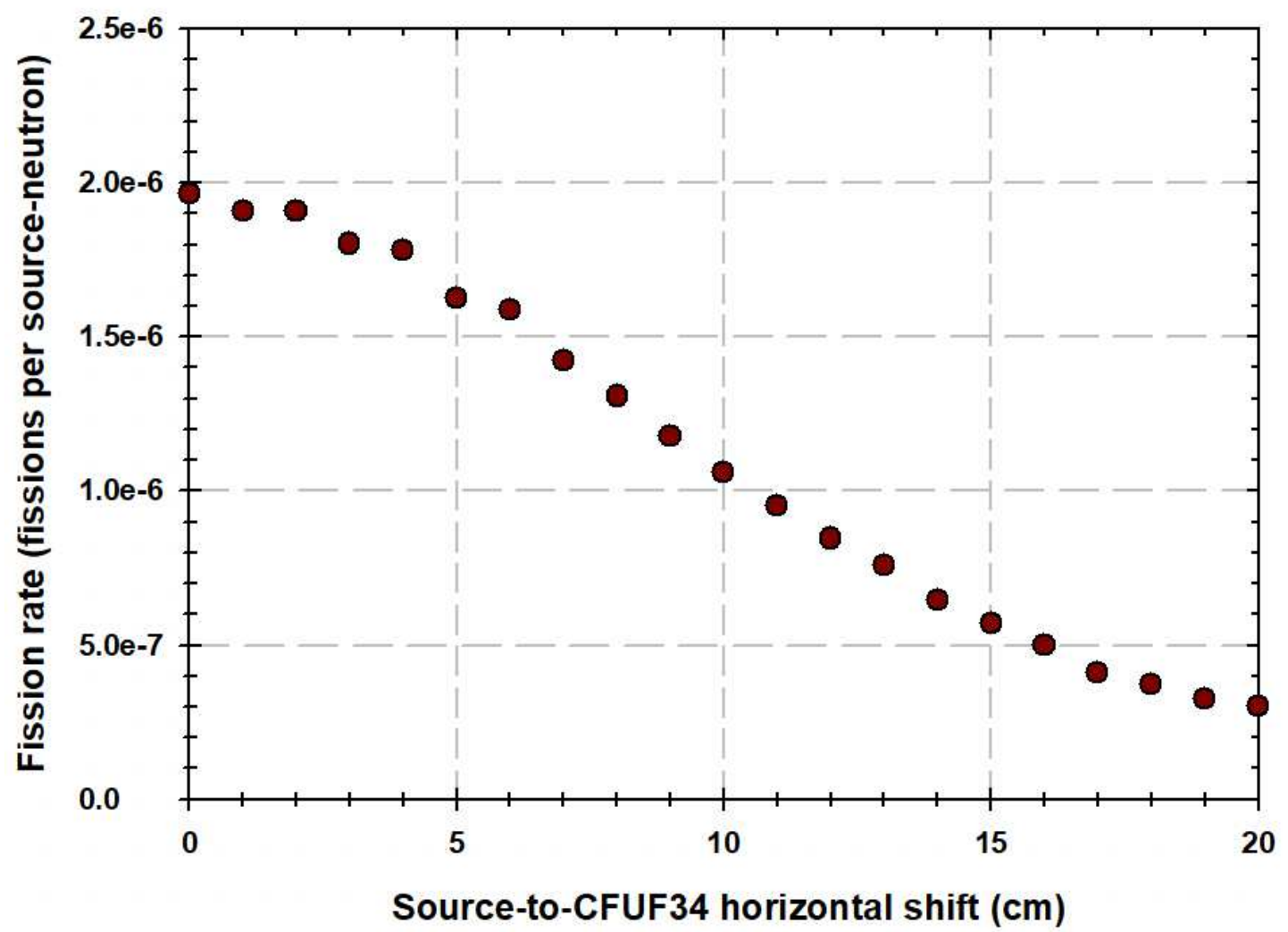

Fig. 6. The fission chamber response as a function of lateral shift when horizontally moved at $1 \mathrm{~cm}$ above fuel debris cylinder. Results obtained for the case of a $10 \mathrm{~cm}$-thick fuel debris cylinder with a diameter of $10 \mathrm{~cm}$.

Thirdly, the potential effect of rotation of the CFUF34 chamber was evaluated by rotating the fission chamber in water from $0^{\circ}$ to $60^{\circ}$, as shown in Fig. 7. The altitude of the fission chamber was maintained at $10 \mathrm{~cm}$ from a point source emitting neutrons according to a ${ }^{244} \mathrm{Cm}$ energy spectrum. Results obtained are 
shown in Fig. 8. The impact of a $60^{\circ}$ rotation of the fission chamber leads to an increase of the signal of $10 \%$ compared to the value obtained in the $0^{\circ}$ reference position. Hence, the rotation of the fission chamber during underwater measurements at Fukushima Daiichi would have a limited impact on signals measured.

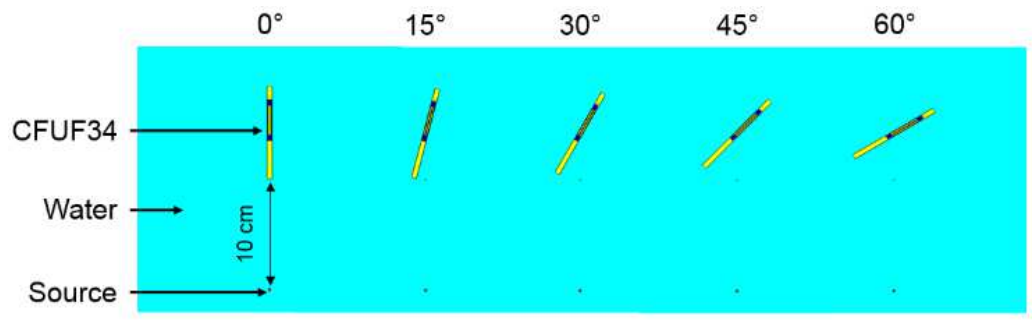

Fig. 7. View of the MCNP6 simulation carried out to estimate the impact of a potential rotation on the fission chamber response.

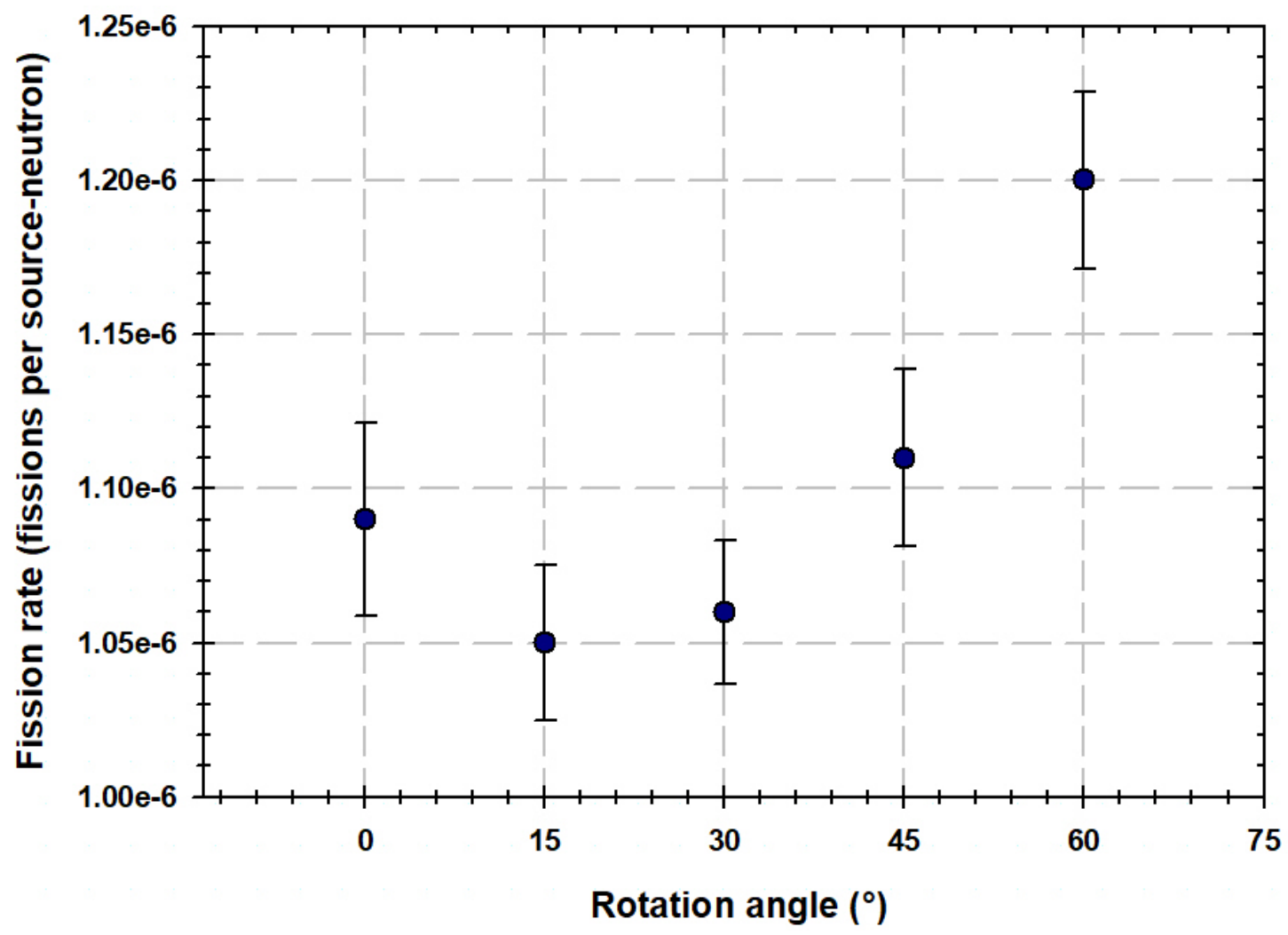

Fig. 8. The fission chamber response as a function of the fission chamber rotation angle. 


\subsection{Effect of sediments above fuel debris}

As mentioned in previous studies $[6,14,15]$, fuel debris may be covered by different substances at the Fukushima Daiichi units. These substances, referred to as "sediments" in this paper, can absorb a part of neutrons emitted by fuel debris below and therefore reduce the measurement sensitivity. Unfortunately, no precise information on these sediments is available at this time in terms of chemical composition, density, or thickness. In this study we simulated sediments as a compact material covering the bottom of the flooded PCV with a chemical composition estimated using data provided by F. Ahmed et al. (2010) [19]: 50.2\% oxygen; $42 \%$ silica; $4.2 \%$ calcium; $3.1 \%$ carbon; $0.3 \%$ iron; and $0.2 \%$ hydrogen. A density of 2.5 g.cm ${ }^{-3}$ was taken from F. Kazi Aoual-Benslafa et al. (2014) [20]. Different thicknesses of sediments were simulated from 0 to $50 \mathrm{~cm}$, with the fission chamber placed at an altitude of $1 \mathrm{~cm}$ from the top of the sediment layer. A view of the MCNP6 model for the case of a $30 \mathrm{~cm}$-thick sediment layer above a 10-cm thick and $50 \mathrm{~cm}$-diameter fuel debris cylinder is shown in Fig. 9 whereas Fig. 10 reports the fission chamber response as a function of the thickness of the sediment layer covering fuel debris. When comparing the fission chamber response obtained with and without a $30 \mathrm{~cm}$-thick sediment layer above fuel debris, measurement sensitivity is reduced by a factor on the order of 10 .
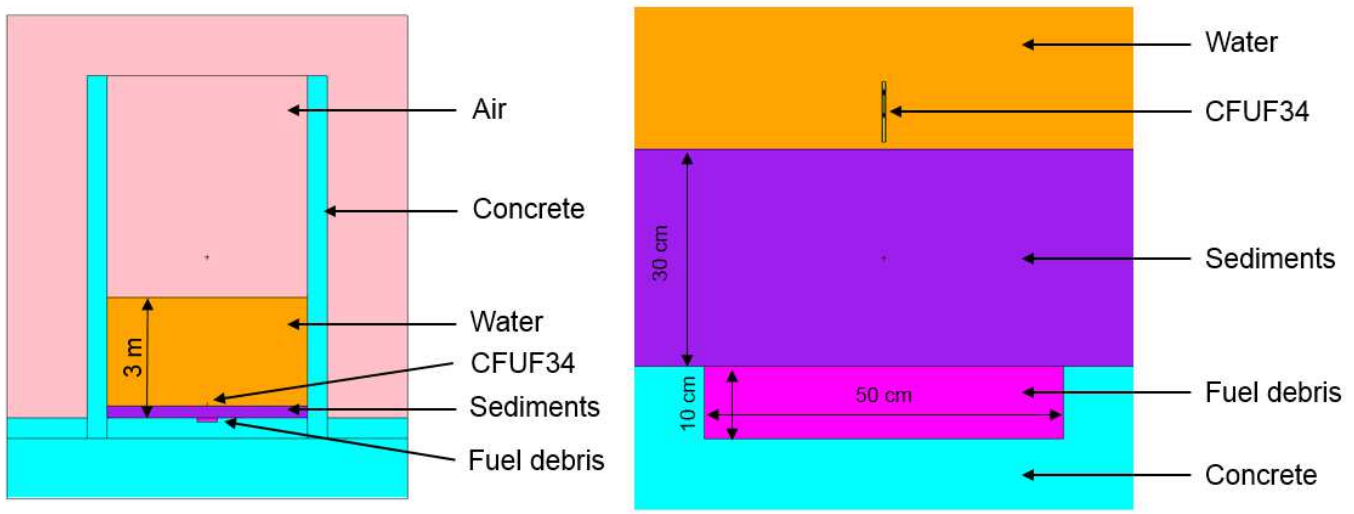

Fig. 9. On the left: view of the MCNP6 model representing the PCV of Fukushima Daiichi unit 1. On the right: focus on the CFUF34 fission chamber immersed in the flooded PCV and pointing towards a cylindrical block of fuel debris covered by sediments. 


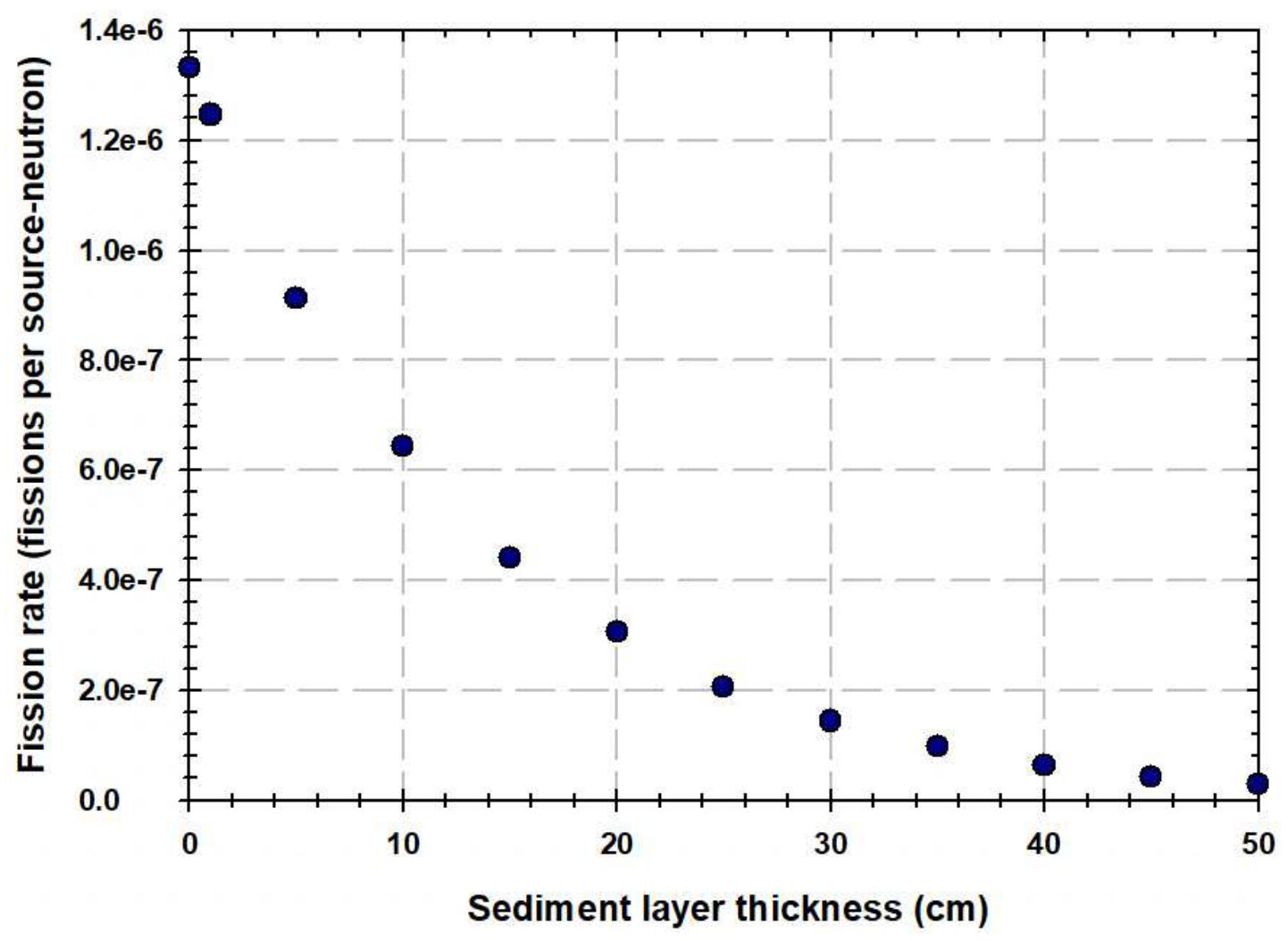

Fig. 10. The fission chamber response as a function of the thickness of the sediment layer covering fuel debris.

\section{Assessment of fission chamber performance under gamma-ray irradiation}

\subsection{Irradiation means}

In order to assess fission chamber performance under high gamma-ray irradiation characterized by different levels of dose rate and different energy spectra, trials were conducted sequentially with three irradiation means: an X-ray tube; an ${ }^{192}$ Ir source; and a linear electron accelerator (linac). The X-ray tube was operated successively with three high voltage values: 176,300 , and $476 \mathrm{kV}$. The ${ }^{192} \mathrm{Ir}$ source was placed in a GAM 120 system and the activity of the source was equal to $2.965 \mathrm{TBq}$ at the date of measurements ( ${ }^{192} \mathrm{Ir}$ has a half-life of 73.827 days [21]). The linac used was the M9-Linatron manufactured by VARIAN (now Varex Imaging) located at the SAPHIR platform (CEA Saclay, France) [22]. This linac generates either 6 or 9 $\mathrm{MeV}$ electrons. On the same principle, the linac and the X-ray tube produce photons by Bremsstrahlung in 
a conversion target. The photon energy spectra are continuous up to an energy depending on the value of electron energy or high voltage selected. In contrast, the ${ }^{192}$ Ir source is characterized by a discrete energy spectrum given in Table 2. Furthermore, the irradiation mode is not the same for the three irradiation means. The X-ray tube and the ${ }^{192}$ Ir source irradiate in a continuous manner whereas the linac generates 2.5 $\mu$ s pulses at a frequency chosen between 40 and $400 \mathrm{~Hz}$ at $6 \mathrm{MeV}$, and between 40 and $385 \mathrm{~Hz}$ at $9 \mathrm{MeV}$. For the case of the linac, the gamma dose rate of interest during the irradiation trials is not the average value but the most intensive one, at which the fission chamber is exposed during a $2.5 \mu$ s pulse. In the following of this paper, gamma dose rates delivered by the linac and expressed in Gy per hour will be given as if the irradiation was continuous. To convert the gamma dose rate measured (averaged on one second of measurement) to the "continuous" gamma dose rate (obtained during the $2.5 \mu$ s pulse), the gamma dose rate measured is divided by the fraction of irradiation time, which is equal to the product between the pulse duration $(2.5 \mu \mathrm{s})$ and the pulse frequency (in $\mathrm{Hz}$ ). The main differences between the three irradiation means are summarized in Table 3. 
Table 2. The six main peaks of the ${ }^{192}$ Ir discrete gamma-ray spectrum [21].

\begin{tabular}{|l|l|}
\hline Energy $(\mathrm{keV})$ & Intensity $(\%)$ \\
\hline 316.51 & 82.75 \\
\hline 468.07 & 47.81 \\
\hline 308.46 & 29.68 \\
\hline 295.96 & 28.72 \\
\hline 604.41 & 8.20 \\
\hline 612.46 & 5.34 \\
\hline
\end{tabular}

Table 3. The main differences between the three irradiation means.

\begin{tabular}{|l|l|l|l|}
\cline { 2 - 4 } \multicolumn{1}{l|}{} & X-ray tube & ${ }^{192}$ Ir source & Linac \\
\hline Irradiation mode & Continuous & Continuous & Pulsed \\
\hline Energy spectra type & Continuous & Discrete & Continuous \\
\hline Maximum photon energy & 176,300, or $476 \mathrm{keV}$ & $612.46 \mathrm{keV}^{1}$ & 6 or $9 \mathrm{MeV}$ \\
\hline
\end{tabular}




\subsection{Experimental protocol}

These experiments were carried out using a CFUE32 fission chamber (manufactured by PHOTONIS) which has the same thermal neutron sensitivity in pulse mode as the CFUF34 fission chamber: $10^{-3}$ (c.s $\left.{ }^{1}\right) /\left(\mathrm{n} \cdot \mathrm{cm}^{-2} \cdot \mathrm{s}^{-1}\right)$. According to the technical specifications provided by PHOTONIS, the CFUE32 fission chamber has a cylindrical shape, a diameter of $7 \mathrm{~mm}$, a total length of $150 \mathrm{~mm}$, and an upper gamma dose rate limit equal to $10^{4} \mathrm{~Gy} \cdot \mathrm{h}^{-1}$. In comparison, the CFUF34 fission chamber has a cylindrical shape, a diameter of $4.7 \mathrm{~mm}$, a total length of $85 \mathrm{~mm}$, and an upper gamma dose rate limit equal to $10^{5} \mathrm{~Gy} \cdot \mathrm{h}^{-1}$.

The CFUE32 fission chamber was connected to a Mirion Technologies (CANBERRA) NIM 7821 module, which provided a high voltage set at $400 \mathrm{~V}$. The signal delivered by the fission chamber was sent to a 7820 ADS (Amplification Discrimination System) which includes a current amplifier from the same company. The discrimination threshold used to separate pulses of interest from the background noise was set at 400 $\mathrm{mV}$. The TTL signal delivered by the 7820 module was sent to an AGILENT counting scale (model 53250A). The latter enabled to register the number of counts detected by the fission chamber.

Two different neutron sources available in the test facilities were used during these experiments. An americium-lithium (AmLi) source was used for experiments performed with the linac and an americiumberyllium (AmBe) source was used for experiments carried out with the ${ }^{192}$ Ir source. Fig. 11 shows respectively the energy spectra of AmLi and AmBe sources simulated with SOURCES-4C [23]. An AmLi source emits neutrons with an average energy of approximately $470 \mathrm{keV}$ whereas an AmBe source emits neutrons with an average energy close to $4 \mathrm{MeV}$. As the CFUE32 fission chamber is mainly sensitive to thermal neutrons, the fission chamber was placed inside a detection block made of polyethylene, in order to increase the signal due to AmLi or AmBe fast neutron sources, and surrounded by a $1 \mathrm{~mm}$-thick cadmium sheet in order to cut thermal neutrons scattered in the irradiation room. 


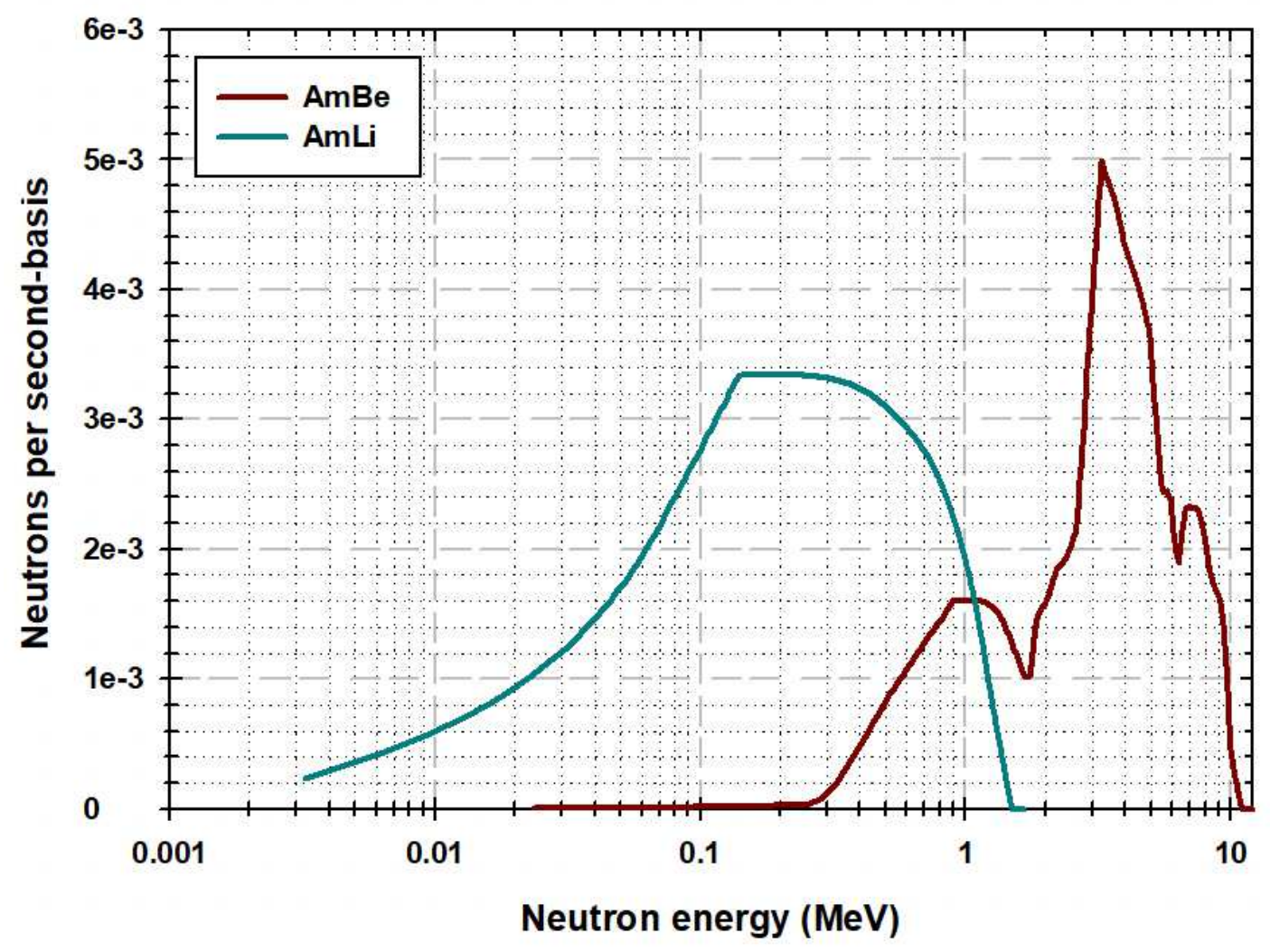

Fig. 11. Energy spectra of AmBe and AmLi neutron sources, simulated with SOURCES-4C [23].

Three types of measurements were performed. First, the bare fission chamber was irradiated by gammarays to evaluate the gamma background signal alone. Secondly, the fission chamber was positioned in the detection block and gamma irradiations were performed in presence of a neutron source next to the detection block to determine the impact of gamma-rays on the neutron signal of interest. Thirdly, in order to assess the fission chamber performance after a strong integrated dose, the fission chamber was exposed in the linac photon beam, and neutron counts were compared before and after irradiation using the same measurement protocol. For these three types of measurements, the gamma dose rates delivered to the fission chamber were measured using an ionization chamber from PTW Freiburg GmbH. This type of detector, often used in the frame of radiation therapy with linear electron accelerators, provides an accurate value of the dose rate in real-time. 
Different levels of gamma dose rates delivered to the fission chamber were tested by changing the distance between the fission chamber (or the detection block) and the ${ }^{192} \mathrm{Ir}$ source or the linac beam. For the X-ray tube, the high-voltage was also used to change the dose rate. For the linac, the fission chamber (or the detection block) was moved inside the photon field at different distances from the electron beam axis. Acquisition time was set at one minute for irradiations performed with either the X-ray tube or the linac, and at ten minutes for irradiations performed with the ${ }^{192} \operatorname{Ir}$ source.

\subsection{Experimental results obtained with the bare fission chamber}

Count rates measured by the bare CFUE32 fission chamber (without the detection block) according to the gamma dose rate delivered by the irradiation mean are gathered in Table 4. Between 43.2 and 2500 Gy.h ${ }^{-1}$, no signal was observed whatever the gamma-ray energy spectra $\left({ }^{192} \operatorname{Ir}\right.$ source, or X-ray tube operated at different high voltages). Measurements between $2790 \mathrm{~Gy} \cdot \mathrm{h}^{-1}$ and $471.6 \mathrm{kGy} \cdot \mathrm{h}^{-1}$ were performed with the linac. From 2790 to $8280 \mathrm{~Gy} \cdot \mathrm{h}^{-1}$, less than two counts were recorded per minute, due to fast photoneutrons emitted by the linac [22] and thermalized in the irradiation hall. From 14.3 to $471.6 \mathrm{kGy} \cdot \mathrm{h}^{-1}$, the count rate varied between a few dozens and a few thousands of counts per minute. The fission chamber is not sensitive to gamma-rays up to a limit of $10 \mathrm{kGy} \cdot \mathrm{h}^{-1}$ as claimed by the manufacturer PHOTONIS. As the gamma dose rate at Fukushima Daiichi should not exceed $1 \mathrm{kGy} \cdot \mathrm{h}^{-1}$, fission chamber measurements performed towards fuel debris localization in the PCVs of the Fukushima Daiichi units would not be affected in this strong gamma dose rate environment. 
Table 4. Count rates measured by the CFUE32 fission chamber according to the gamma dose rate delivered by the irradiation mean.

\begin{tabular}{|c|c|c|}
\hline Irradiation mean & Dose rate $\left(G y \cdot h^{-1}\right)$ & Counts per minute \\
\hline \multirow{3}{*}{ X-ray tube } & 43.2 & 0 \\
\hline & 48.5 & 0 \\
\hline & 61.8 & 0 \\
\hline${ }^{192} \operatorname{Ir}$ source & 852 & 0 \\
\hline \multirow{3}{*}{ X-ray tube } & 954 & 0 \\
\hline & 1119 & 0 \\
\hline & 2500 & 0 \\
\hline \multirow{8}{*}{ Linac } & 2790 & 1 \\
\hline & 3690 & 0 \\
\hline & 5520 & 0 \\
\hline & 8280 & 2 \\
\hline & 14300 & 58 \\
\hline & 21500 & 11741 \\
\hline & 111600 & 2752 \\
\hline & 471600 & 2805 \\
\hline
\end{tabular}




\subsection{Experimental results obtained with the detection block}

The number of counts measured by the CFUE32 fission chamber inside the polyethylene and cadmium detection block according to the gamma dose rate delivered by the ${ }^{192} \mathrm{Ir}$ source in presence of an AmBe neutron source are presented in Table 5, taking into account statistical uncertainties. Neutron counts are constant and not disturbed by the gamma dose rate. Measurements performed with an AmLi neutron source and the linac confirmed that this conclusion was still valid at $10^{3} \mathrm{~Gy} \cdot \mathrm{h}^{-1}$.

Table 5. Number of counts measured by the CFUE32 fission chamber according to the gamma dose rate delivered by the ${ }^{192}$ Ir source in presence of an AmBe neutron source.

\begin{tabular}{|c|c|c|}
\hline Irradiation mean & Dose rate $\left(\mathrm{Gy} \cdot \mathrm{h}^{-1}\right)$ & Number of counts \\
\hline \multirow{4}{*}{${ }^{192}$ Ir source } & $\sim 0$ & $253 \pm 16$ \\
\cline { 2 - 3 } & 3.25 & $244 \pm 16$ \\
\cline { 2 - 3 } & 6.57 & $274 \pm 17$ \\
\cline { 2 - 3 } & 27.64 & $252 \pm 16$ \\
\cline { 2 - 3 } & 56.62 & $259 \pm 16$ \\
\hline
\end{tabular}

During the test aiming at assessing the fission chamber performance after a high integrated dose, the linac photon beam delivered 2200 Gy to the fission chamber in ten minutes. The numbers of counts obtained before and after irradiation, is respectively: $335 \pm 18$ and $333 \pm 18$. Despite the high integrated dose, no performance degradation of the fission chamber was encountered. 


\section{Conclusion and outlook}

In this study, we investigated the performance of fission chamber towards fuel debris localization in the damaged reactors of Fukushima Daiichi by MCNP6 simulation. The calculated neutron flux under water showed that fuel debris should be sought by their thermal neutron signature at a distance of a few centimeters. Then, we simulated the response profiles of a CFUF34 fission chamber as a function of altitude or lateral shift with respect to fuel debris, which will be used in future work to develop fuel debris localization algorithm. We also showed that rotational movements of the fission chamber up to $60^{\circ}$ would have a limited impact on signals measured. Sensitivity loss due to sediments potentially covering fuel debris has been evaluated on the order of a factor 10 considering a $30 \mathrm{~cm}$-thick sediment layer.

Secondly, we assessed fission chamber performance under gamma-ray irradiation at different levels of dose rates and with different energy spectra. Trials were conducted with a CFUE32 fission chamber with an Xray tube, an ${ }^{192}$ Ir source, and a linac. These experiments enable to draw the conclusion that the fission chamber is not impacted by the gamma dose rate up to $10^{4} \mathrm{~Gy} \cdot \mathrm{h}^{-1}$, which is in good agreement with specifications provided by the manufacturer (PHOTONIS). It is important to emphasize that the energy spectra of the gamma-ray sources did not have an impact either. In addition, no performance degradation was observed after an integrated gamma dose of $2200 \mathrm{~Gy}$ on the fission chamber in a 10 minute irradiation. However, when the fission chamber is irradiated by gamma dose rates above $10^{4} \mathrm{~Gy} \cdot \mathrm{h}^{-1}$ (upper limit of the operating domain specified by PHOTONIS), a significant gamma background is observed. Nevertheless, as the gamma dose rates at Fukushima Daiichi should not exceed $10^{3} \mathrm{~Gy} \cdot \mathrm{h}^{-1}$, fission chamber measurements performed towards fuel debris localization in the Primary Containment Vessels (PCV) of the units would not be affected by the severe gamma-ray irradiation.

Next steps should consist in designing and testing a measurement system including a fission chamber integrated on the carrier of a robot. Trials should first be performed in the laboratory using neutron sources in order to acquire experimental data and refine the measurement protocol. On the other hand, fuel debris 
localization algorithms are being studied [11] and future work will also aim at fine-tuning the reconstruction algorithm in view of improving spatial resolution of fuel debris localization. 


\section{Funding}

This work was supported by Mitsubishi Research Institute, Inc. 


\section{References}

[1] TEPCO, Investigation results of the inside of unit 3's primary containment vessel (PCV), 2015, available at: https://www7.tepco.co.jp/wp-content/uploads/hd03-02-04-001-001-05-handouts_151020_01e.pdf

[2] TEPCO, Locating fuel debris inside the unit 2 reactor using a muon measurement technology at Fukushima Daiichi nuclear power station, 2016, available at: http://www.tepco.co.jp/en/nu/fukushimanp/handouts/2016/images/handouts_160728_01-e.pdf

[3] TEPCO, Locating fuel debris inside the unit 3 reactor using a muon measurement technology at Fukushima Daiichi nuclear power station, 2017, available at: http://www.tepco.co.jp/en/nu/fukushimanp/handouts/2017/images/handouts_170928_01-e.pdf

[4] TEPCO, The 5th Progress report on the investigation and examination of unconfirmed and unresolved issues on the Fukushima Daiichi nuclear accident, 2017, available at: http://www.tepco.co.jp/en/decommision/accident/images/171225e0101.pdf

[5] T. Nagatani, M. Komeda, T. Shiba, Y. Nauchi, M. Maeda, H. Sagara, H. Kosuge, M. Kureta, H. Tomikawa, K. Okumura, C. Heinberg, K. Hori, Characterization study of four candidate technologies for nuclear material quantification in fuel debris at Fukushima Daiichi nuclear power station, Energy Procedia, $131(2017) 258-263$.

[6] L. Fernandez-Moguel, A. Rydl, T. Lind, Updated analysis of Fukushima unit 3 with MELCOR 2.1. Part 1:Thermal-hydraulic analysis, Annals of Nuclear Energy, 123 (2019) 59 - 77.

[7] K. Takamatsu, H. Takegami, C. Ito, K. Suzuki, H. Ohnuma, R. Hino, T. Okumura, Cosmic-ray muon radiography for reactor core observation, Annals of Nuclear Energy, 78 (2015) 166 - 175.

[8] P.C. Burns, R.C. Ewing, A. Navrotsky, Nuclear fuel in a reactor accident, Science, Vol. 335, Issue 6073 (2012) $1184-1188$. 
[9] A. Kirishima, M. Hirano, D. Akiyama, T. Sasaki, N. Sato, Study on the leaching behavior of actinides from nuclear fuel debris, Journal of Nuclear Materials, 502 (2018) 169 - 176.

[10] D.H. Beddingfield, N.H. Johnson, H.O. Menlove, ${ }^{3} \mathrm{He}$ neutron proportional counter performance in high gamma-ray dose environments, Nuclear Instruments and Methods in Physics Research A, 455 (2000) $670-682$.

[11] J. Dumazert, R. Coulon, F. Carrel, A. Sari, C. Thiam, M. Trocmé, Q. Lecomte, H. Hamrita, R. Woo, F. Lainé, C. Frangville, M. Bakkali, K. Boudergui, B. Krausz, R. Pissarello, R. Delalez, Inverse problem approach for the underwater localization of Fukushima Daiichi fuel debris with fission chambers, Nuclear Inst. and Methods in Physics Research, A (2018), https://doi.org/10.1016/j.nima.2018.10.025.

[12] C.J. Werner, J.S. Bull, C.J. Solomon, F.B. Brown, G.W. McKinney, M.E. Rising, D.A. Dixon, R.L. Martz, H.G. Hughes, L.J. Cox, A. J. Zukaitis, J.C. Armstrong, R.A. Forster, L. Casswell, MCNP Version 6.2 Release Notes, Los Alamos National Laboratory, LA-UR-18-20808, 2018.

[13] C. Journeau, J. Monneris, B. Tormos, L. Brissonneau, E. Excoffier, V. Testud, C. Chagnot, D. Roulet, Fabricating Fukushima Daiichi in-vessel and ex-vessel fuel debris simulants for the development and qualification of laser cutting technique, Proc. ERMSAR-2017 (Eur. Rev. Mtg Sev. Accident Res.), Poland, Warsaw, 2017.

[14] S.M. An, J.H. Song, J.-Y. Kim, H.Y. Kim, M. Naitoh, Experimental investigation on molten pool representing corium composition at Fukushima Daiichi nuclear power plant, Journal of Nuclear Materials, 478 (2016) $164-171$.

[15] H. Bonneville, L. Carénini, M. Barrachin, Fukushima core melt composition simulation with ASTEC, $16^{\text {th }}$ International Topical Meeting on Nuclear Reactor Thermalhydraulics (NURETH-16), Chicago, USA, 2015. 
[16] P. Chatelard, N. Reinke, S. Arndt, S. Belon, L. Cantrel, L. Carénini, K. Chevalier-Jabet, F. Cousin, J. Eckel, F. Jacq, C. Marchetto, C. Mun, L. Piar, ASTEC V2 severe accident integral code main features, current V2.0 modelling status, perspectives, Nuclear Engineering and Design, 272 (2014) 119 - 135.

[17] D. Reilly, N. Ensslin and H. Smith Jr., S. Kreiner, Passive nondestructive assay of nuclear materials, NUREG/CR-5550, LA-UR-90-732, 1991.

[18] C.J. Werner (editor), "MCNP Users Manual - Code Version 6.2", LA-UR-17-29981, 2017.

[19] F. Ahmed, M.H. Bibi, K. Seto, H. Ishiga, T. Fukushima, B.P. Roser, Abundances, distribution, and sources of trace metals in Nakaumi-Honjo coastal lagoon sediments, Japan, Environmental Monitoring and Assessment, 167 (2010) 473 - 491.

[20] F. Kazi Aoual-Benslafa, M. Ameur, B. Mekerta, A. Semcha, Caractérisation des sédiments de dragage du barrage de Bouhanifia pour une réutilisation, XIII ${ }^{\text {mes }}$ Journées Nationales Génie Côtier - Génie Civil, France, Dunkerque, 2014.

[21] E. Browne (LBNL), BNM - CEA/LNHB, Table de Radionucléides, Ir-192, available at: http://www.lnhb.fr/nuclides/Ir-192_tables.pdf

[22] A. Sari, F. Carrel, F. Lainé, Characterization and optimization of the photoneutron flux emitted by a 6or 9-MeV electron accelerator for neutron interrogation measurements, IEEE Trans. Nucl. Sci., Vol. 65, No. 9 (2018) 2539 - 2546.

[23] W.B. Wilson, R.T. Perry, E.F. Shores, W.S. Charlton, T.A. Parish, G.P. Estes, T.H. Brown, E.D. Arthur, M. Bozoian, T.R. England, D.G. Madland, and J.E. Stewart, SOURCES 4C: a code for calculating (alpha,n) spontaneous fission, and delayed neutron sources and spectra, LA-UR-02-1839, 2002. 